\title{
Bulk properties of isentropic mixing into the tropics in the lower stratosphere
}

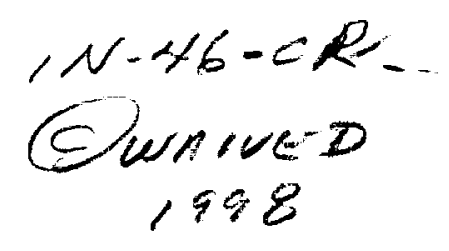

K. Minschwaner, ${ }^{1}$ A. E. Dessler, ${ }^{2}$ J. W. Elkins, ${ }^{3}$ C. M. Volk, ${ }^{3,4}$ D. W. Fahey, ${ }^{5}$ 046216 M. Loewenstein, ${ }^{6}$ J. R. Podolske, ${ }^{6}$ A. E. Roche, ${ }^{7}$ and K. R. Chan ${ }^{6}$

Abstract. Timescales for mixing of midlatitude air into the tropical lower stratosphere are deduced from observations of long-lived tracers $\mathrm{N}_{2} \mathrm{O}$ and $\mathrm{CCl}_{3} \mathrm{~F}$. Bulk mixing between tropical and midlatitude regions is assumed to be isentropic and relatively slow compared with local mixing within each region. The mean value of the mixing timescale ranges from 12 to 18 months near $20 \mathrm{~km}$. There is a tendency for shorter mixing times at higher and lower altitudes, although vertical profiles of mixing cannot be definitively established by the data. A more robust quantity is given by the fraction of midlatitude air entrained into the tropical upwelling region. Implied mixing fractions exceed $50 \%$ above $22 \mathrm{~km}$.

\section{Introduction}

It has long been recognized that the observed distributions of stratospheric water vapor and ozone imply upward transport across the tropical tropopause and a mean meridional circulation characterized by ascent in the tropics and subsidence at higher latitudes [Brewer, 1949; Dobson, 1956]. Early work by Newell [1963] on the dispersal of ${ }^{185} \mathrm{~W}$ bomb debris and more recent studies of sulfate aerosol distributions [Trepte and Hitchman, 1992] show the persistence of maxima in tracer fields within $20^{\circ}$ of the equator and between 21 and $28 \mathrm{~km}$ altitude. These observations indicate a barrier to mixing with the extratropics, at least in comparison to rapid irreversible mixing within midlatitude "surf zones" [McIntyre and Palmer, 1984]. Poleward transport across the subtropical barrier appears to be associated with planetary wave activity, such as the tongues of air stretching from the tropics into midlatitudes reported by Randel et al. [1993]. These features have been

\footnotetext{
${ }^{1}$ Department of Physics, New Mexico Institute of Mining and Technology, Socorro.

${ }^{2}$ NASA Goddard Space Flight Center, Greenbelt, Maryland.

${ }^{3}$ Climate Monitoring and Diagnostics Laboratory, NOAA Boulder, Colorado.

4 Also at the Cooperative Institute for Research in Environmental Sciences, Boulder, Colorado.

${ }^{5}$ Aeronomy Laboratory, NOAA, Boulder, Colorado.

${ }^{B}$ NASA Ames Research Center, Moffett Field, California.

${ }^{7}$ Lockheed Palo Alto Research Laboratory, Palo Alto, California.
}

Copyright 1996 by the American Geophysical Union.

Paper number 96J000335.

0148-0227/96/96JD-00335505.00 identified also in transport model simulations [Waugh, 1993; Chen et al., 1994]. At lower altitudes, measurements of $\mathrm{N}_{2} \mathrm{O}$ and $\mathrm{H}_{2} \mathrm{O}$ suggest that mixing out of the tropics is much more efficient, occurring on a timescale of 3 months or less below $22 \mathrm{~km}$ [Hintsa et al., 1994].

The above studies emphasized transport from the tropics to midlatitudes, but an equally important issue is the mixing of midlatitude air into the tropics. The timescale associated with mixing into the tropics is a key factor in assessing the stratospheric effect of high-speed civil transport. Model calculations indicate that the sensitivity of ozone loss rates to perturbations in $\mathrm{NO}_{x}$ levels are much greater at $30 \mathrm{~km}$ than at 20 $\mathrm{km}$ [Considine et al., 1995]. It is thus important to understand the extent to which aircraft exhaust emitted at midlatitudes may be mixed into the tropics and carried to higher altitudes where its effect on ozone is significant. Observations of long-lived gases and reactive compounds $\mathrm{NO}_{y}$ and $\mathrm{O}_{3}$ indicate a small, but possibly important, amount of in-mixing from the extratropics [Avallone and Prather, 1996]. Here we examine the bulk properties of stratospheric mixing into the tropics through analysis of long-lived tracer fields obtained from balloon, aircraft, and satellite platforms. The observations are coupled to a diagnostic formulation for tropical tracer budgets which permits estimation of the mean rate of isentropic mixing from midlatitudes to the tropics in the lower stratosphere.

\section{Observations}

We focus on two long-lived species, $\mathrm{N}_{2} \mathrm{O}$ (nitrous oxide) and $\mathrm{CCl}_{3} \mathrm{~F}$ (CFC-11). Sources for both gases are confined to the troposphere, and the sinks are due primarily to photodissociation in the stratosphere. Global, steady state lifetimes are calculated to be 123 and 44 years for $\mathrm{N}_{2} \mathrm{O}$ and $\mathrm{CCl}_{3} \mathrm{~F}$, respectively [Minschwaner et al., 1993]. Local photochemical lifetimes at $22 \mathrm{~km}$ in the tropics are considerably smaller, of the order of 25 years 
for $\mathrm{N}_{2} \mathrm{O}$ and 1 year for $\mathrm{CCl}_{3} \mathrm{~F}$ in the annual mean. The wide range of photochemical time constants between these two species is useful for the problem at hand, as effects of isentropic mixing are more easily quantified if the mixing timescale is shorter than the local photochemical lifetime. Another consideration, however, is the mean difference between tropical and midlatitude mixing ratios along a given isentropic surface.

Figures 1 and 2 show balloon and aircraft measurements of tropical $\mathrm{CCl}_{3} \mathrm{~F}$ (Figure 1) and $\mathrm{N}_{2} \mathrm{O}$ (Figure 2) spanning $5^{\circ} \mathrm{S}$ to $10^{\circ} \mathrm{N}$ by Goldan et al. [1980] and Vedder et al. [1978, 1981]. Midlatitude data shown in Figures 1 and 2 are from $41^{\circ} \mathrm{N}$ by Goldan et al. [1980]. The Goldan et al. $\mathrm{N}_{2} \mathrm{O}$ data are adjusted according to the correction factor recommended by Goldan et al. [1981]. Uncertainties for these data range from $10 \%$ to $25 \%$. All observations were made during the period 1976 to 1979 and are scaled to 1980 using a height-independent factor derived from observed trends in the troposphere [Elkins et al., 1993]. The altitude coordinate of the original data is mapped to annual mean isentropes in Figures 1 and 2 using climatological pressure and temperature fields [Anderson et al., 1986].

Curves drawn through the data in Figures 1 and 2 are least squares, quadratic exponential fits ( $y=$ $\left.\exp \left(a x^{2}+b x+c\right)\right)$ which are used in the subsequent analysis. The limited amount of tropical data precludes the use of a nonparametric fit for this work. Choice of the quadratic exponential function is guided by the expected form of the tropical vertical profile in the absence of isentropic mixing, as discussed below. In addition, this is one of the lowest order functions that can reproduce the correct asymptotic limits $(0$ at $\infty$, ap-

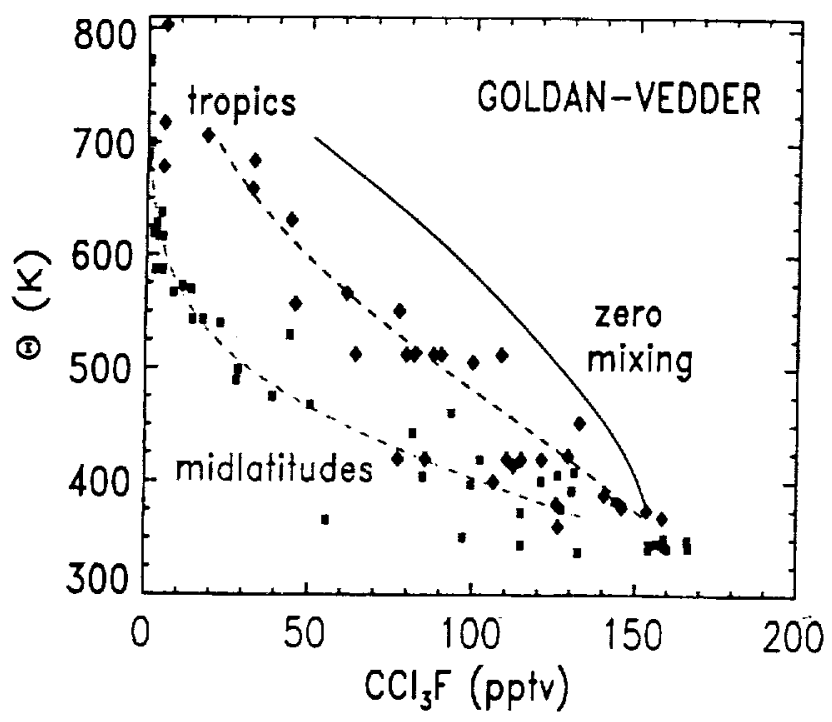

Figure 1. $\mathrm{CCl}_{3} \mathrm{~F}$ mixing ratios obtained from balloon and aircraft measurements by Goldan et al. [1980] and Vedder et al. $[1978,1981]$ mapped to climatological potential temperature as discussed in the text. Black diamonds are data obtained between $5^{\circ} \mathrm{S}$ and $10^{\circ} \mathrm{N}$; gray squares are for data from $41^{\circ} \mathrm{N}$. Dashed curves are least squares fits to the data. The solid curve labeled "zero mixing" is calculated according to (2).

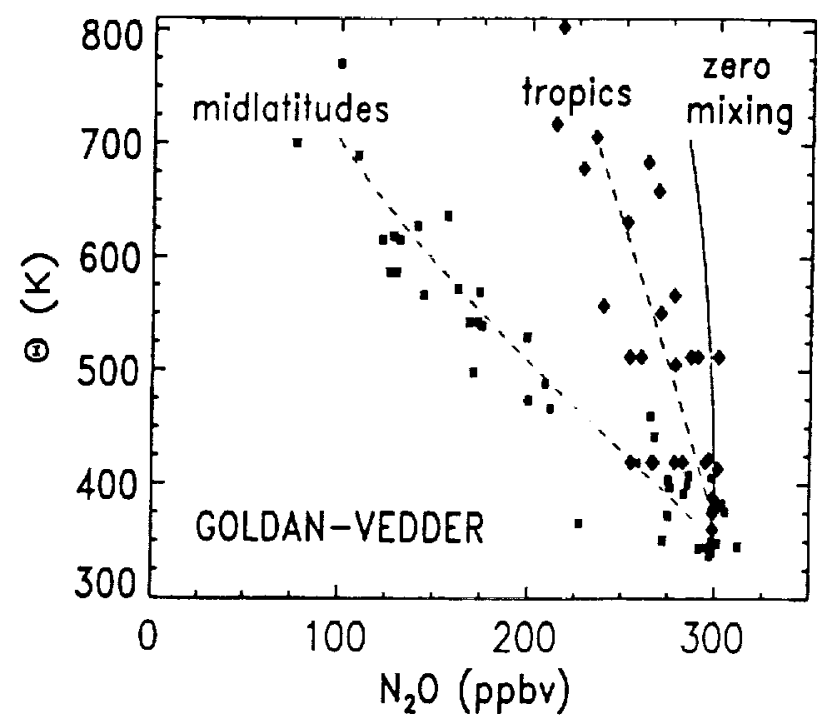

Figure 2. Same as Figure 1 but for mixing ratios of $\mathrm{N}_{2} \mathrm{O}$.

proximately constant mixing ratio below tropopause) and has been used previously by Ehhalt et al. [1983] to best describe their measurements of tracer vertical profiles at midlatitudes. All of our least-squares fits are constrained to match tropospheric values [Elkins et al., 1993] at the tropopause.

The data shown in Figure 3 consists of $\mathrm{CCl}_{3} \mathrm{~F}$ measurements obtained by the National Oceanic and Atmospheric Administration (NOAA) Airborne Chromatograph for Atmospheric Trace Species (ACATS-4) onboard the NASA ER 2 aircraft [Elkins et al., 1996]. The observations were made during the Airborne Southern Hemisphere Ozone Experiment Measurements for Assessing the Effects of Stratospheric Aircraft (ASHOE/ MAESA) (March-November 1994), and the Stratospheric Photochemistry, Aerosol, and Dynamics Expedition (SPADE) using ACATS-2 (May 1993). Midlatitude data consist of measurements between $30^{\circ}$ to $40^{\circ}$ latitude. Discrimination against anomalously high or low data influenced by the short-term effects of planetary wave activity is accomplished using modified potential vorticity (MPV) [Lait, 1994] as a quasi-conserved tracer. The midlatitude data are constrained by values of MPV between $8 \times 10^{-6}$ and $1.6 \times 10^{-5} \mathrm{~K} \mathrm{~m}^{2} \mathrm{~kg}^{-1} \mathrm{~s}^{-1}$. MPV is obtained from daily National Meteorological Center analyses and interpolated to the measurement location. Tropical $\mathrm{CCl}_{3} \mathrm{~F}$ data, defined here for $\pm 15^{\circ}$ latitude and $|\mathrm{MPV}|<6 \times 10^{-6} \mathrm{~K} \mathrm{~m}^{2} \mathrm{~kg}^{-1} \mathrm{~s}^{-1}$, were obtained only during ASHOE/MAESA. The uncertainty of each measurement is estimated to be $<3 \%$.

Figure 4 presents $\mathrm{N}_{2} \mathrm{O}$ measurements obtained from the SPADE and ASHOE/MAESA ER 2 flights. During SPADE, $\mathrm{N}_{2} \mathrm{O}$ was measured by the ATLAS tunable diode laser instrument [Podolske and Loewenstein, 1993]. The measurement uncertainty is $5 \%(1 \sigma)$. Measurements of $\mathrm{N}_{2} \mathrm{O}$ during ASHOE/MAESA are taken from the NOAA ACATS instrument. These data have a 


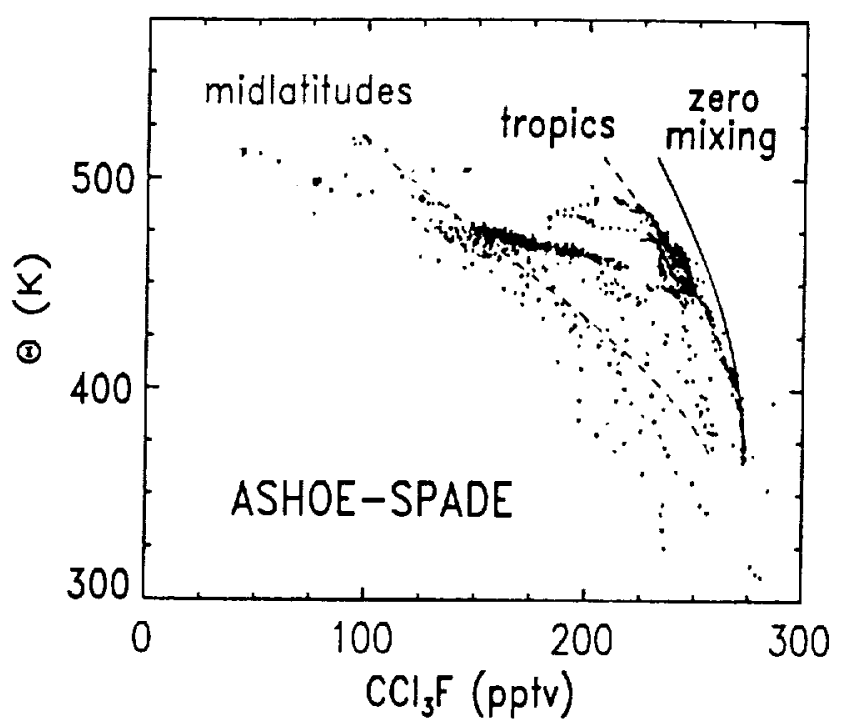

Figure 3. $\mathrm{CCl}_{3} \mathrm{~F}$ mixing ratios measured during ER 2 flights from the Airborne Southern Hemisphere Ozone Experiment - Measurements for Assessing the Effects of Stratospheric Aircraft (ASHOE/MAESA) and the Stratospheric Photochemistry, Aerosol, and Dynamics Expedition (SPADE) missions, as a function of potential temperature obtained by simultaneous measurements of pressure and temperature. Black points are from $\pm 15^{\circ}$ latitude with $|\mathrm{MPV}| \leq 6 \times 10^{-6}$ $\mathrm{K} \mathrm{m}^{2} \mathrm{~kg}^{-1} \mathrm{~s}^{-1}$; gray points are from $30^{\circ}-40^{\circ} \mathrm{N}$ with $8 \times 10^{-6}<\mathrm{MPV}<1.6 \times 10^{-5} \mathrm{~K} \mathrm{~m}^{2} \mathrm{~kg}^{-1} \mathrm{~s}^{-1}$. As in Figure 1, dashed curves are fits to the data and the solid curve is the zero mixing solution given by (2).

measurement uncertainty of less than $3 \%$. Nearly all of the ER 2 data lie below the $500 \mathrm{~K}$ isentropic level. At higher $\theta$, the data shown in Figure 4 are from the Cryogenic Limb Array Etalon Spectrometer (CLAES) [Roche et al., 1993] onboard the Upper Atmosphere Research Satellite, measured between February 12 and March 16, 1993. Typical uncertainties in these CLAES $\mathrm{N}_{2} \mathrm{O}$ measurements are approximately $20 \%$. Discrimination of all $\mathrm{N}_{2} \mathrm{O}$ data into midlatitude and tropical bins is performed on the basis of latitude and MPV, as discussed above for $\mathrm{CCl}_{3} \mathrm{~F}$.

\section{Calculations}

Inputs of $\mathrm{CCl}_{3} \mathrm{~F}$ and $\mathrm{N}_{2} \mathrm{O}$ to the stratosphere are governed primarily by the cross-tropopause flux in the tropics. The local budget of these tracers in the tropical lower stratosphere is dominated by effects of upward transport, photochemical loss, and mixing with the extratropics. Focusing exclusively on the tropics, the continuity equation for the tropical mixing ratio $\chi$ of either gas is given by

$$
\frac{\partial \chi}{\partial t}+\dot{\theta} \frac{\partial \chi}{\partial \theta}+L_{\chi}+\frac{1}{\tau}\left(\chi-\chi^{\prime}\right)=0
$$

where $\theta$ is potential temperature, $\dot{\theta}$ is the rate of radiative heating, $L$ is the photochemical loss rate, and $\chi^{\prime}$

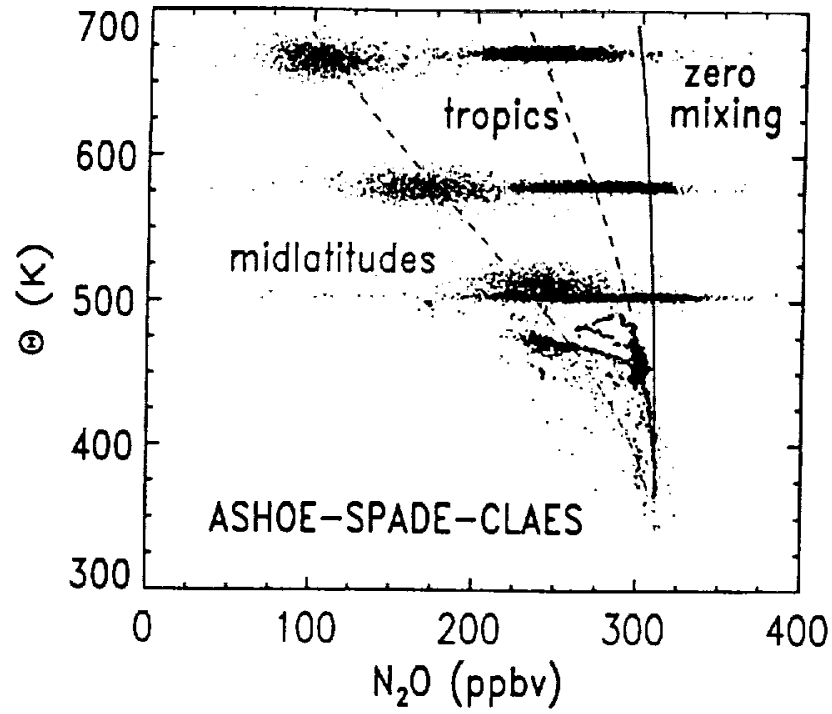

Figure 4. Same as Figure 3 , except for $\mathrm{N}_{2} \mathrm{O}$ from the ASHOE/MAESA and SPADE ER-2 missions. Data above about $500 \mathrm{~K}$ are from the CLAES satellite instrument on board the UARS satellite.

is the midlatitude mixing ratio. Quasi-horizontal mixing along surfaces of constant potential temperature is parameterized using a mixing timescale $\tau$. This is the local timescale for mixing into the tropics on a given isentropic surface. Our approach assumes that isentropic mixing between tropics and midlatitudes is slow compared with mixing confined solely within each region. This point of view is supported by bomb and volcanic debris studies as well as observations of differences in tracer correlations between tropical and midlatitude regimes [Murphy et al., 1993].

Using the analytic fits to the measured vertical profiles of $\chi, \chi^{\prime}, \partial \chi / \partial \theta$, and calculated values of $\dot{\theta}$ and $L$, we can apply (1) to determine $\tau$ as a function of $\theta$. Photochemical loss $(L)$ due to ultraviolet photodissociation is calculated using the high-resolution radiation code described by Minschwaner et al. [1993] and includes effects of scattering in the 190-210 nm spectral region. These loss rates give rise to calculated values of global and local lifetimes noted previously. The $\mathrm{N}_{2} \mathrm{O}$ loss includes a small contribution (about $10 \%$ ) due to reaction with $O\left({ }^{1} D\right)$. Long-term atmospheric growth rates $(\partial \chi / \partial t)$ are specified from analysis of tropospheric measurements (see Elkins et al. [1993] for discussion of methods). This term is small compared with either vertical advection or photochemical loss except in the case of $\mathrm{CCl}_{3} \mathrm{~F}$ data by Goldan et al. [1980] and Vedder et al. $[1978,1981]$ (hereinafter referred to as Goldan-Vedder), where 1980 growth rates were $5.7 \%$ per year.

Radiative heating $(\dot{\theta})$ is calculated using the Community climate Model 2 radiative transfer code [Briegleb, 1992a, b] initialized with tropical temperature, ozone, and water vapor profiles observed during the Central Equatorial Pacific Experiment [Dessler et al., 1946]. Tropospheric clouds amounts are specified according to annual mean values from the International Satellite 
Cloud Climatology Project [Rossow and Schiffer, 1991]. Longwave fluxes to space and shortwave albedo are in good agreement with measurements from the Earth Radiation Budget Experiment [Barkstrom, 1984]. Figure 5 shows the vertical profile of radiative heating. Implied ascent velocities in the tropical lower stratosphere (about $0.025 \mathrm{~km} \mathrm{day}^{-1}$ ) are consistent with the mean value determined by Holton [1990] on the basis of global mass balance.

\section{Results}

The zero mixing curves shown in Figures 1-4 are solutions to the homogeneous form of (1) using calculated values of $\dot{\theta}$ and $L$. That is, we set $T=\infty$ and solve for $\chi$ under the assumption of no tropical-midlatitude mixing. The vertical profile thus takes the form of an exponential

$$
\chi=\chi^{o} \exp \left(-\int_{\theta_{0}}^{\theta} \frac{L+\gamma}{\dot{\theta}} d \theta\right)
$$

where $\gamma=(1 / \chi)(\partial \chi / \partial t)$ is the long-term growth rate, $\theta_{o}$ is the potential temperature of the tropopause, approximately $375 \mathrm{~K}$, and $\chi^{\circ}$ is the tropopause mixing ratio. The argument to the exponential function in (2) for both gases is well approximated by a quadratic polynomial, thus motivating the use of quadratic exponential fits to the observed vertical profiles.

The poor agreement shown in Figures 1-4 between the zero mixing solutions and tropical data is a clear indication of entrainment of midlatitude air into the tropical ascent region. The discrepancies are not related to errors in computed photochemical loss: uncertainties in photolysis frequencies are no larger than $20 \%$ [Minschwaner et al., 1993] which cannot explain the differ-

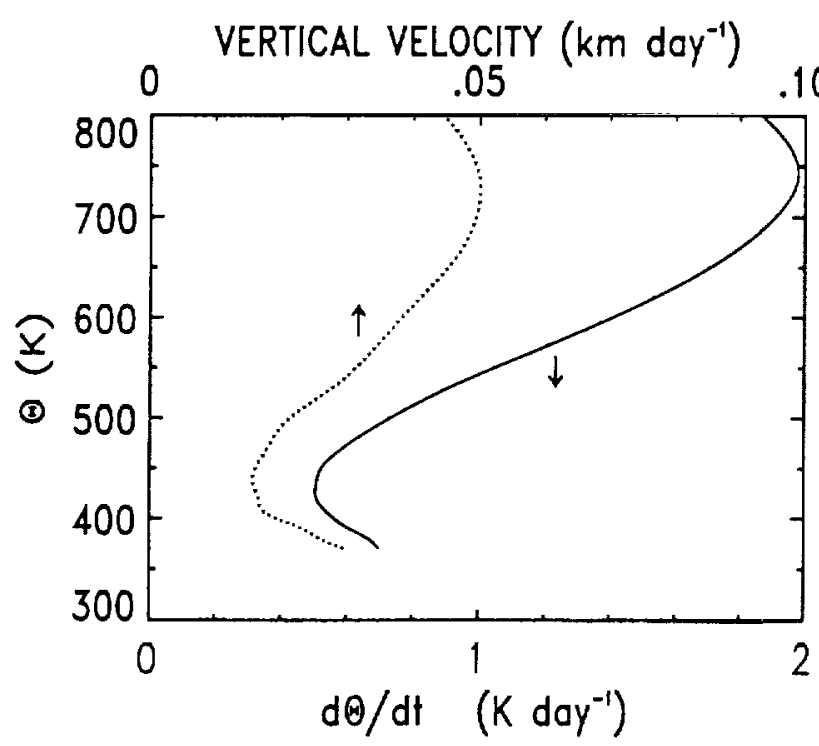

Figure 5. Calculated values of $\dot{\theta}$ used in (1) (solid curve, lower axis). Approximate vertical velocities are indicated by the dotted curve (upper axis). ence between the zero mixing curve and the data. Possible errors in computed radiative heating also cannot be responsible, since it is easily shown that (2) gives rise to a power law relationship between $\mathrm{CCl}_{3} \mathrm{~F}$ and $\mathrm{N}_{2} \mathrm{O}$ mixing ratios which is independent of the diabatic heating rate:

$$
\chi_{\mathrm{CCl}_{3} \mathrm{~F}}=\chi_{\mathrm{CCl}_{3} \mathrm{~F}}^{o}\left(\frac{\chi_{\mathrm{N}_{2} \mathrm{O}}}{\chi_{\mathrm{N}_{2} \mathrm{O}}^{o}}\right)^{K}
$$

where $K(\approx 22$ in the tropical lower stratosphere) is the ratio of $\mathrm{CCl}_{3} \mathrm{~F}$ to $\mathrm{N}_{2} \mathrm{O}$ loss plus growth terms (the numerator of the integrand in (2) above). We found large differences between the power law relation and the tropical $\mathrm{CCl}_{3} \mathrm{~F}-\mathrm{N}_{2} \mathrm{O}$ correlations obtained from Figures 1 and 2 , indicating that the zero mixing discrepancies cannot be due primarily to errors in computed radiative heating rates.

As mentioned above, timescales for isentropic mixing between the tropics and midlatitudes can be obtained from (1) using a combination of calculated quantities and mean vertical tracer profiles (analytic fits) based on the observations shown in Figures 1-4. Timescales derived in this fashion are shown in Figure 6. Owing to the higher measurement accuracies and availability of simultaneous observations of potential temperature, there is reason to place a higher weight on results from the ASHOE, SPADE, and CLAES (hereinafter referred to as A-S-C) data. These mixing time profiles are in fact bracketed by results from the Goldan-Vedder analyses shown in Figure 6.

Despite large differences in absolute magnitudes, a common feature of all data sets is the relatively slow mixing between about 430 and $500 \mathrm{~K}(19-21 \mathrm{~km})$. Faster

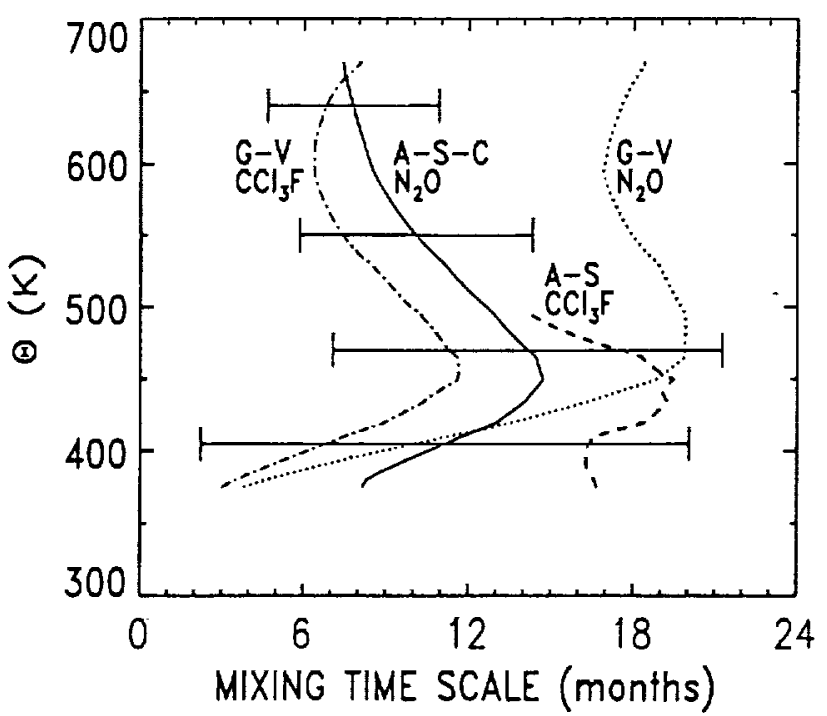

Figure 6. Timescale for mixing into the tropics based on fits to the data shown in Figure 1 (dash-dot, labeled G-V (Goldan-Vedder) $\mathrm{CCl}_{3} \mathrm{~F}$ ), Figure 2 (dotted, labeled $\mathrm{G}-\mathrm{V} \mathrm{N}_{2} \mathrm{O}$ ), Figure 3 (dashed, labeled A-S (ASHOESPADE) $\mathrm{CCl}_{3} \mathrm{~F}$ ), and Figure 4 (solid, labeled A-S-C (ASHOE-SPADE-CLAES) $\mathrm{N}_{2} \mathrm{O}$ ). Error bars represent the level of uncertainty for the A-S-C $\mathrm{N}_{2} \mathrm{O}$ derived mixing time, as shown in Figure 7. 
rates of mixing are indicated above and below this implied barrier, although these tendencies should be viewed with caution in light of the large level of uncertainty (see below). Nevertheless, it is of interest to note that the morphology of mixing suggested from Figure 6 is similar to that observed for export out of the polar vortices [e.g., Schoeberl et al., 1992]; slow mixing in both cases is associated with strong gradients in potential vorticity [Trepte and Hitchman, 1992; Plumb et al., 1994].

Uncertainties in the derived mixing times are estimated to be about $55 \%$ near $450 \mathrm{~K}$, decreasing to $40 \%$ $46 \%$ above $500 \mathrm{~K}$ in the case of the A-S-C N $\mathrm{N}_{2} \mathrm{O}$ mixing time. Contributions to this uncertainty are displayed in Figure 7 which also includes the total uncertainty assuming that individual components add in quadrature. Calculated values of radiative heating ( $\pm 20 \%-25 \%$ including effects of tropical cirrus) and photochemical loss ( $\pm 15 \%-20 \%$ [Minschwaner et al., 1993]) both make contributions to the overall uncertainty. Additionally, the large scatter of the data introduces uncertainties in our $\chi^{\prime}, \chi$, and $\partial \chi / \partial \theta$ terms in (1). In regions where the quantity $\chi-\chi^{\prime}$ is comparable to the uncertainties in $\chi$ and $\chi^{\prime}$, such as below $400 \mathrm{~K}$, computed mixing times are uncertain by at least a factor of 2 .

Owing to the large temporal range of the data, our results represent mean values averaged over at least 1 year. These mixing times thus represent the bulk effect of entrainment into the tropical lower stratosphere

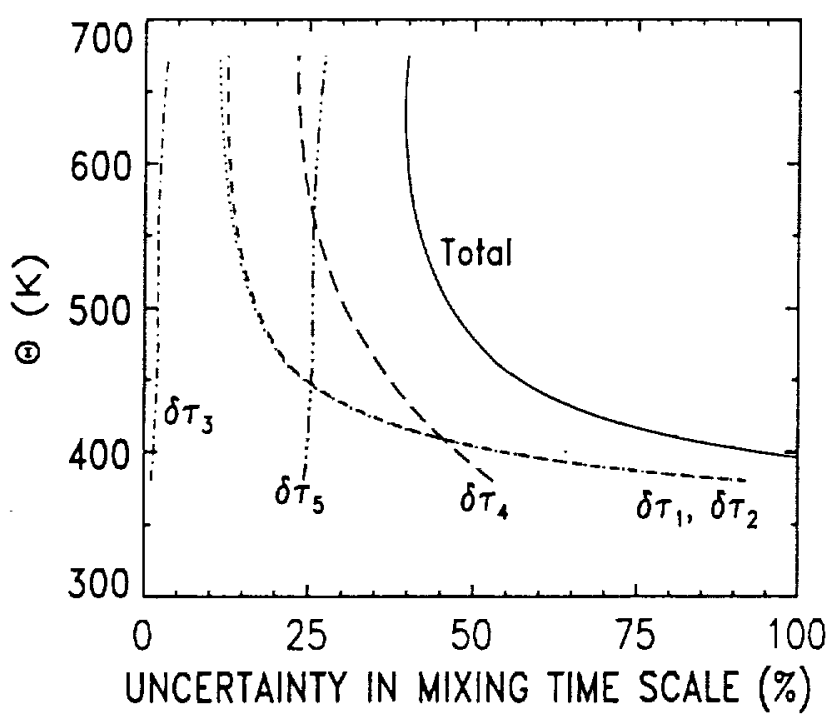

Figure 7. Components to the uncertainty for the A-S$\mathrm{C} \mathrm{N}_{2} \mathrm{O}$ mixing timescale shown in Figure 6 . The curves labeled $\delta \tau_{1}$ and $\delta \tau_{2}$ are contributions from uncertainties in $\chi$ and $\chi^{\prime}$, respectively, assuming these uncertainties both increase with $\theta$ from 7 to $15 \mathrm{ppb}$ within the altitudes of interest; $\delta \tau_{3}$ is due to an $18 \%$ uncertainty in $L$; $\delta \tau_{4}$ arises from a $50 \%$ uncertainty in $\partial \chi / \partial \theta$ at $380 \mathrm{~K}$, decreasing to $20 \%$ at $650 \mathrm{~K}$; and $\delta \tau_{5}$ originates from a $23 \%$ uncertainty in $\dot{\theta}$. Total uncertainty is calculated by adding the individual components in quadrature. Uncertainties for the other mixing profiles shown in Figure 6 are generally larger. due to synoptic and planetary scale wave mixing. The strength of the subtropical barrier may also depend on season as well as the phase of the quasibiennial oscillation in tropical winds and temperature [Hitchman et al., 1994], but these effects are beyond the scope of this paper. Model simulations also suggest hemispheric differences in mixing out of the tropics [Chen et al., 1994]. We found small hemispheric differences in the CLAES midlatitude distributions, although the impact on computed mixing into the tropics was not significant.

Species used in this analysis must satisfy two criteria. First, the local photochemical lifetime in the tropics must be larger than the derived mixing time so that the effect of mixing is apparent in the tropical profile. Second, there must be a clear distinction between tropical and midlatitude profiles (given by $\chi-\chi^{\prime}$ in (1)). We believe $\mathrm{N}_{2} \mathrm{O}$ is better suited for this analysis because (1) the local photochemical lifetime exceeds 1 year in the tropics below about $28 \mathrm{~km}$ and (2) the reaction with $\mathrm{O}^{1} D$ becomes more important at middle and high latitudes in setting the total loss rate, thus producing a sufficiently large gradient between tropical and midlatitude profiles. Our highest confidence therefore lies in results from the A-S-C $\mathrm{N}_{2} \mathrm{O}$ data. It is not clear why timescales derived from the Goldan-Vedder $\mathrm{N}_{2} \mathrm{O}$ data are significantly larger above $500 \mathrm{~K}$.

A quantity of interest is the fraction of midlatitude air $\zeta$ entrained into the tropical ascent region. If (1) is rewritten in terms of the difference $\Delta$ between the tropical and midlatitude mixing ratio of an infinitely long-lived tracer in steady state $(L=0, \partial / \partial t=0)$ and we define $\zeta=\left(\Delta_{0}-\Delta\right) / \Delta_{0}$, where $\Delta_{0}$ is the initial difference at the isentropic surface intersecting the tropical tropopause, then $\zeta$ is determined by

$$
\zeta(\theta)=1-\exp \left(-\int_{\theta_{0}}^{\theta} \frac{1 / \tau}{\dot{\theta}} d \theta\right)
$$

Owing to the altitude dependence of mixing and tracer vertical profiles, this quantity is not the same as the apparent mixing fraction derived along surfaces of constant $\theta$. For example, the apparent mixing fraction (obtained by simply comparing the observed and zero mixing profiles on a constant theta level) for the A-S-C N $\mathrm{N}_{2} \mathrm{O}$ data is about $30 \%$ at $650 \mathrm{~K}$. As shown below, the actual fraction of midlatitude air is approximately $65 \%$. The reason this value is much higher than the apparent mixing fraction is that much of the mixing is occurring at lower altitudes where the difference between the tropical and midlatitude mixing ratios is smaller.

Figure 8 shows the calculated profiles of $\zeta$ corresponding to mixing timescales from Figure 6 . Differences between data sets are less than $40 \%$ above $500 \mathrm{~K}$ despite much larger disparities in profiles of $\tau$; apparently, $\zeta$ is a more robust quantity for the present method of analysis. As an indication of the effect of uncertainties in the vertical profile of $\tau$, Figure 8 also includes a $\zeta$ profile corresponding to a fixed $\tau$ of 12 months. The fraction of midlatitude air entrained into the tropics increases from $0 \%$ at the tropopause to more than $50 \%$ above $550 \mathrm{~K}$ 


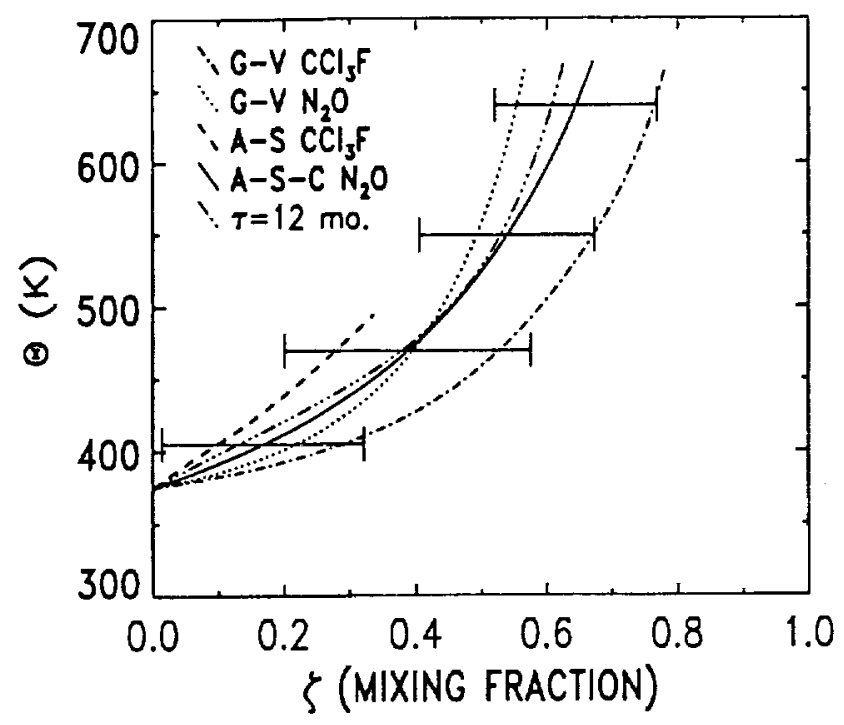

Figure 8. Fraction of midlatitude air entrained into the tropics based on the mixing time curves shown in Figure 6 (see (4) and discussion in text). Additionally, a $\zeta$ profile is shown that corresponds to a fixed $\tau$ of 12 months, independent of $\theta$. Error bars represent the level of uncertainty for the mixing fraction derived from the A-S-C $\mathrm{N}_{2} \mathrm{O}$ analysis which includes the uncertainty in $\tau$ and in $\dot{\theta}$. The latter uncertainty, however, very nearly cancels in the expression for $\zeta$.

for all cases except the ASHOE-SPADE $\mathrm{CCl}_{3} \mathrm{~F}$ profile, which reaches $32 \%$ at $490 \mathrm{~K}$. Note that the definition of midlatitude used here does not distinguish between the ultimate origins of midlatitude air parcels, only that they have spent sufficient time in the extratropics to acquire midlatitude characteristics of long-lived tracer amounts.

Our results for ascent with quasi-continuous mixing are qualitatively consistent with observations of the upward propagating seasonal signal of $2 \mathrm{xCH}_{4}+\mathrm{H}_{2} \mathrm{O}$ presented by Mote et al. [1996]. They found that the amplitude of the seasonal signal (comparable to $1-\zeta$ in the present analysis) diminished sharply between the tropopause and about the $500 \mathrm{~K}$ level but changed much less rapidly at higher altitudes, in agreement with the mixing fractions shown here in Figure 8 . The signal attenuation below $500 \mathrm{~K}$ implies a lower limit to the mixing timescale of 7 to 9 months, also in agreement with our values of $\tau$ shown in Figure 6 . However, the lower limit of 15-18 months derived by Mote et al. between 500 and $700 \mathrm{~K}$ is somewhat longer than our best estimate given by the A-S-C $\mathrm{N}_{2} \mathrm{O}$ data in Figure 6 .

\section{Conclusion}

The distributions of long-lived tracers $\mathrm{N}_{2} \mathrm{O}$ and $\mathrm{CCl}_{3} \mathrm{~F}$ in the lower stratosphere indicate that a potential barrier exists for isentropic mixing of midlatitude air into the tropics. The tropical stratosphere may be effectively isolated for more than 1 year between 430 and $500 \mathrm{~K}$. Although enhanced rates of mixing are inferred above and below this region, the level of uncertainty does not preclude the possibility of a fixed value of $\tau$, independent of $\theta$. Additional data from the tropical lower stratosphere, for example, from the ongoing Stratospheric Tracers of Atmospheric Transport missions, would be highly desirable to more effectively constrain mean tropical profiles of long-lived tracers. It is unlikely, however, that the present method can be used to unambiguously derive a vertical profile of mixing in which variations with respect to $\theta$ will exceed the level of uncertainty. The mean timescales derived here suggest that further analysis would be best suited using $\mathrm{N}_{2} \mathrm{O}$ or molecules with similar photochemical time constants, such as $\mathrm{CCl}_{2} \mathrm{~F}_{2}$ (CFC-12). Recent work by Volk et al. (In situ measurements constraining exchange between the tropics and the middle latitudes in the lower stratosphere, submitted to Science, 1996) has provided mean mixing times below $490 \mathrm{~K}$ by employing tracer correlations and involving a more extensive suite of source gases and photochemically active species. Their mean in-mixing time of 13.6 months below $490 \mathrm{~K}$ agrees favorably with values reported here.

The implied entrainment of midlatitude air into the tropical ascent region is remarkably large; up to $50 \%$ of the air above the $550 \mathrm{~K}$ surface is of midlatitude origin. Recently, Plumb [1996] has described a conceptual "pipe" model of the tropical ascent region which successfully addresses shortcomings in the Plumb and Ko [1992] global mixing formulation. We find evidence here which supports a pipe-like behavior in the lower stratosphere. Owing to the integrated effect of isentropic mixing, however, the tropical import barrier appears to possess an altitude-dependent permeability.

Acknowledgments. We thank S. C. Wofsy and R. J. Salawitch for useful discussions on the analysis of the balloon tracer data, and Christos Zerefos for his efforts as guest editor of this manuscript. The radiative heating code was provided by J. T. Kiehl and B. P. Briegleb of the Climate and Global Dynamics Division of the National Center for Atmospheric Research. K.M. acknowledges support from the UARS Guest Investigator Program, grant NAG 5-2847. Support for A.E.D. was provided through a postdoctoral fellowship from the National Research Council.

\section{References}

Anderson, G. P., S. A. Clough, F. X. Kneizys, J. H. Chetwynd, and E. P. Shettle, AFGL atmospheric constituent profiles (0-120km), AFGL Tech. Rep., AFGL-TR-860110,43 pp., Air Force Phillips Lab., Hansom Air Force Base, Mass., 1986.

Avallone, L. M., and M. J. Prather, Photochemical evolution of ozone in the lower tropical stratosphere, J. Geophys. Res., 101, 1457-1461, 1996.

Barkstrom, B. R., The Earth Radiation Budget Experiment (ERBE), Bull. Am. Meteorol. Soc., 65, 1170-1185, 1984.

Briegleb, B. P., Delta-Eddington approximation for solar radiation in the NCAR community climate model, J. Geophys. Res., 97, 7603-7612, $1992 \mathrm{a}$.

Briegleb, B. P., Longwave band model for thermal radiation in climate studies, J. Geophys. Res., 97, 11,475-11,485, $1992 b$. 
Brewer, A. W., Evidence for a world circulation provided by measurements of helium and water vapor distribution in the stratosphere, $Q$. J. R. Meteorol. Soc., 75, 351-363, 1949.

Chen, P., J. R. Holton, A. O'Neill, and R. Swinbank, Isentropic mass exchange between the tropics and extratropics in the stratosphere, J. Atmos. Sci., 51, 3006-3018, 1994.

Considine, D. B., A. R. Douglass, and C. H. Jackman, Sensitivity of two-dimensional model predictions of ozone response to stratospheric aircraft: An update, J. Geophys. Res., 100, 3075-3090, 1995.

Dessler, A. E., K. Minschwaner, E. M. Weinstock, E. J. Hintsa, J. G. Anderson, and J. M. Russell, III, The effects of tropical cirrus clouds on the abundance of lower stratospheric ozone, J. Atmos. Chem., 23, 209-220, 1996.

Dobson, G. M. B., Origin and distribution of polyatomic molecules in the atmosphere, Proc. Roy. Soc. London, A, 236, 187-193, 1956.

Ehhalt, D. H., E. P. Röth, and U. Schmidt, On the temporal variance of stratospheric trace gas concentrations, $J$. Atmos. Chem., 1, 27-51, 1983.

Elkins, J. W., T. M. Thompson, T. H. Swanson, J. H. Butler, B. D. Hall, S. O. Cummings, D. A. Fisher, and A. G. Raffo, Decrease in the growth rates of atmospheric chlorofluorocarbons 11 and 12, Nature, 364, 780-783, 1993.

Elkins, J. W., et al., Airborne gas chromatograph for in situ measurements of long-lived species in the upper troposphere and lower stratosphere, Geophys. Res. Lett., 24, 347-350, 1996.

Goldan, P. D., W. C. Kuster, D. L. Albritton, and A. L. Schmeltekopf, Stratospheric $\mathrm{CFCl}_{3}, \mathrm{CF}_{2} \mathrm{Cl}_{2}$, and $\mathrm{N}_{2} \mathrm{O}$ height profile measurements at several latitudes, J. Geophys. Res., 85, 413-423, 1980.

Goldan, P. D., W. C. Kuster, A. L. Schmeltekopf, F. C. Fehsenfeld, and D. L. Albritton, Correction of atmospheric $\mathrm{N}_{2} \mathrm{O}$ mixing ratio data, J. Geophys. Res., 86, $5385-5386,1981$.

Hintsa, E. J., et al., SPADE $\mathrm{H}_{2} \mathrm{O}$ measurements and the seasonal cycle of stratospheric water vapor, Geophys. Res. Lett., 21, 2559-2562, 1994.

Hitchman, M. H., M. McKay, and C. R. Trepte, A climatology of stratospheric aerosol, J. Geophys. Res., 99, 20,689$20,700,1994$.

Holton, J. R., On the global exchange of mass between the stratosphere and troposphere, J. Atmos. Sci., 47, 392$395,1990$.

Lait, L. R., An alternative form for potential vorticity, $J$. Atmos. Sci., 51, 1754-1759, 1994.

McIntyre, M. E., and T. N. Palmer, The "surf zone" in the stratosphere, J. Atmos. Terr. Phys., 46, 825-849, 1984.

Mote, W. M., K. H. Rosenlof, M. E. McIntyre, E. S. Carr, J. C. Gille, J. R. Holton, J. S. Kinnersley, H. C. Pumphrey, J. M. Russel III, and J. W. Waters, An atmospheric tape recorder: The imprint of tropical tropopause temperatures on stratospheric water vapor, J. Geophys. Res., 101, 3989-4006, 1996.

Minschwaner, K., R. J. Salawitch, and M. B. McElroy, Absorption of solar radiation by $\mathrm{O}_{2}$ : Implications for $\mathrm{O}_{3}$ and lifetimes of $\mathrm{N}_{2} \mathrm{O}, \mathrm{CFCl}_{3}$, and $\mathrm{CF}_{2} \mathrm{Cl}_{2}, J$. Geophys. Res., 98, 10,543-10,561, 1993 .

Murphy, D. M., et al., Reactive nitrogen and its correlation with ozone in the lower stratosphere and upper troposphere, J. Geophys. Res., 98, 5325-5332, 1993.
Newell, R. E., Transfer through the tropopause and within the stratosphere, Q. J. R. Meteorol. Soc., 89, 167-204, 1963.

Plumb, R. A., A "tropical pipe" model of stratospheric transport, J. Geophys. Res., 101, 3957-3972, 1996.

Plumb, R. A., and M. K. W. Ko, Interrelationships between mixing ratios of long-lived stratospheric constituents, $J$. Geophys. Res., 97, 10,145-10,156, 1992.

Plumb, R. A., et al., Intrusions into the lower stratospheric Arctic vortex during the winter of 1991-1992, J. Geophys. Res., 99, 1089-1105, 1994.

Podolske, J. R., and M. Loewenstein, Airborne tunable diode laser spectrometer for trace-gas measurement in the lower stratosphere, Appl. Opt. 32, 5324-5333, 1993.

Randel, W. J., et al., Stratospheric transport from the tropics to middle latitudes by planetary-wave mixing, Nature, 365, 533-535, 1993.

Roche, A. E., J. B. Kumer, J. L. Mergenthaler, G. A. Ely, W. G. Uplinger, J. F. Potter, T. C. James, and L. W. Sterritt, The Cryogenic Limb Array Spectrometer (CLAES) on UARS: experiment description and performance, $J$. Geophys. Res., 98, 10763-10776, 1993.

Rossow, W. B., and R. A. Schiffer, ISCCP cloud data products, Bull. Am. Meteorol. Soc., 72, 2-20, 1991.

Schoeberl, M. R., L. R. Lait, P. A. Newman, and J. E. Rosenfield, The structure of the polar vortex, $J$. Geophys. Res., 97, 7859-7882, 1992.

Trepte, C. R., and M. H. Hitchman, Tropical stratospheric circulation deduced from satellite aerosol data, Nature, 355, 626-628, 1992.

Vedder, J. F., B. J. Tyson, R. B. Brewer, C. A. Boitnott, and E. C. Y. Inn, Lower stratosphere measurements of variation with latitude of $\mathrm{CF}_{2} \mathrm{Cl}_{2}, \mathrm{CFCl}_{3}, \mathrm{CCl}_{4}$, and $\mathrm{N}_{2} \mathrm{O}$ profiles in the northern hemisphere, Geophys. Res. Lett., 5, 33-36, 1978.

Vedder, J. F., E. C. Y. Inn, B. J. Tyson, and C. A. Boitnott, Measurements of $\mathrm{CF}_{2} \mathrm{Cl}_{2}, \mathrm{CFCl}_{3}$, and $\mathrm{N}_{2} \mathrm{O}$ in the lower stratosphere between $2^{\circ} \mathrm{S} 73^{\circ} \mathrm{N}$ latitude, J. Geophys. Res., 86, 7363-7368, 1981 .

Waugh, D. W., Subtropical stratospheric mixing linked to disturbances in the polar vortices, Nature, $365,535-537$, 1993.

K. R. Chan, M. Loewenstein, and J. R. Podolske, NASA Ames Research Center, Moffett Field, CA 94035.

A. E. Dessler, NASA Goddard Space Flight Center, Greenbelt, MD 20771.

J. W. Elkins and C. M. Volk, Climate Monitoring and Diagnostics Laboratory, NOAA, Boulder, CO 80303. 80303 .

D. W. Fahey, Aeronomy Laboratory, NOAA, Boulder, CO

K. Minschwaner, Department of Physics, New Mexico Institute of Mining and Technology, Socorro, NM, 87801. krm@kestrel.nmt.edu.

A. E. Roche, Lockheed Palo Alto Research Laboratory, Palo Alto, CA 94303.

(Received August 8, 1995; revised January 16, 1996; aceepted January, 1996.) 